\title{
O APRENDIZADO DA UTILIZAÇÃO DA SUBSTITUIÇÃO SENSORIAL VISUO-TÁTIL POR PESSOAS COM DEFICIÊNCIA VISUAL: PRIMEIRAS EXPERIÊNCIAS E ESTRATÉGIAS METODOLÓGICAS
}

\author{
Virgínia Kastrup \\ Universidade Federal do Rio de Janeiro, Rio de Janeiro, Brasil \\ Eliana Sampaio \\ Conservatoire National des Arts et Métiers, Paris, França \\ Maria Clara de Almeida \\ Filipe Herkenhoff Carijó \\ Universidade Federal do Rio de Janeiro, Rio de Janeiro, Brasil
}

\begin{abstract}
RESUMO: O sistema de substituição tátil-visual (TVSS) é uma tecnologia assistiva criada para ajudar deficientes visuais a perceberem aspectos visuais de seu ambiente através do tato e contribuir para sua inclusão social. Para melhor entender o processo de aprendizagem dessa tecnologia, quatro participantes cegos foram treinados com o Brainport ${ }^{\circledR}$, a última versão do TVSS, onde imagens visuais transformadas são exploradas pela língua. O artigo objetiva de investigar o estágio inicial desse processo de aprendizagem, em termos tanto do desempenho dos participantes quanto da qualidade de sua experiência. O treinamento, conduzido de acordo com um método clínico-pedagógico, produziu dados em terceira pessoa e em primeira pessoa. Os dados foram obtidos através de registros de desempenho e de entrevistas de explicitação. Os resultados mostram que as maiores dificuldades surgidas foram relativas ao acoplamento sensório-motor, aos movimentos do corpo e da cabeça e à dissonância entre as expectativas e a qualidade da experiência perceptiva.
\end{abstract}

PALAVRAS-CHAVE: tecnologia cognitiva; tecnologia assistiva; substituição sensória; deficiência visual; aprendizado de tecnologias.

\section{THE LEARNING OF THE USE OF THE TACTILE-VISION SENSORY SUBSTITUTION BY PEOPLE WITH VISUAL DISABILITY: FIRST EXPERIENCES AND METHODOLOGICAL STRATEGIES}

\begin{abstract}
The tactile-vision-substitution-system (TVSS) is an assistive technology designed to aid the visually impaired in perceiving visual aspects of their environment located beyond touch. In order to better understand the learning process of that assistive aid, we trained four blind participants with the Brainport ${ }^{\mathbb{R}}$, the last version of the TVSS, where the transformed visual images are explored by the tongue. More specifically, this article aims to investigate the initial stage of this learning process, in terms both of participants' performance and their qualitative experience. The training, conducted according to the clinical-pedagogic method, produced data both from the first-person and the third-person point of view. Data were gathered through records of participants' performance and explanation interviews. Results show that the main difficulties arising during the process concerned sensory-motor coupling, body and head movement, and the gap between actual and expected quality of the perceptual experience.
\end{abstract}

KEYWORDS: cognitive technology; assistive technology; sensory substitution; visual impairment; technology learning

Engenheiros, educadores e terapeutas sabem que os esforços para o desenvolvimento e utilização de tecnologia assistiva para pessoas com deficiência são muitas vezes fadados ao fracasso. Ideias brilhantes, associadas a implementações tecnológicas de alta qualidade, resultam frequentemente em dispositivos que não são utilizados pelo público alvo de pessoas com deficiência. Alguns protótipos não ultrapassam a fase experimental. Quanto aos produtos especializados, testados e comercializados, observa-se um rechaço, acarretando o abandono definitivo por parte das pessoas com deficiência, situado em torno de 30\% (Phillips \& Zhao, 1993). Estudos 
que analisam esse problema sugerem, para corrigi-lo, a implicação das pessoas com deficiência em toda as fases decisivas da produção e a escolha de uso de tais dispositivos (Riemer-Reiss \& Wacker, 2000).

Numa legítima preocupação científica, os dados obtidos nas pesquisas com a substituição sensorial visual se referem majoritariamente a uma população homogênea, de pessoas relativamente jovens, com perfis diagnósticos semelhantes e características sócioeconômicas comparáveis (Chebat, Rainville Kurpers, \& Ptito, 2007; Sampaio, Maris, \& Bach-y-Rita, 2001; Segond, Weiss, \& Sampaio, 2005). Ora, uma das grandes características da população com deficiência visual é justamente a heterogeneidade, com uma tendência crescente de maior concentração de pessoas idosas. Por outro lado, pouca atenção foi dada, naquelas pesquisas, à experiência dos utilizadores. Numa abordagem exploratória, o objetivo do presente trabalho consiste em investigar, principalmente do ponto de vista da experiência das pessoas cegas voluntárias, a etapa inicial do processo de aprendizagem do dispositivo de substituição sensorial visuo-tátil BrainPort ${ }^{\mathbb{Q}}$.

$\mathrm{Na}$ maior parte das vezes, os estudos sobre o aprendizado dos dispositivos de substituição sensorial têm sido baseados em métodos de terceira pessoa, que destacam a aquisição de uma performance, com ênfase nos aspectos quantitativos do aprendizado (número de horas, de acertos e erros). Numa outra direção, estudos em primeira pessoa foram realizados por G. Guarniero. Cego congênito e pesquisador, Guarniero $(1974,1977)$ relatou seu próprio processo de treinamento para o uso do dispositivo de substituição sensorial. Em termos metodológicos, o trabalho de Guarniero apresenta uma descrição pessoal do processo de aprendizagem, que enfatiza a novidade da experiência e os avanços seguidos passo a passo durante o treino. Discussões recentes têm enfatizado a necessária complementaridade entre métodos de terceira e primeira pessoa para o estudo da cognição. Varela e Shear (1999) reuniram trabalhos que apresentam desenvolvimentos atuais de métodos de primeira pessoa, que envolvem estratégias bem definidas para o acesso à experiência vivida e que ultrapassam a mera auto-observação. Uma parte dessas estratégias envolve a participação de uma segunda pessoa, cujo papel é guiar o processo de acesso à experiência. Estudos na área de deficiência visual têm buscado produzir dados em primeira pessoa, através de abordagens em segunda pessoa (Kastrup, 2007, 2008). Através desse procedimento, damos voz aos próprios deficientes visuais, criando a possibilidade de que, através de suas falas, sua experiência seja socialmente compartilhada. Um dos desafios dos métodos de primeira pessoa é não trazer apenas representações prévias e opiniões dos sujeitos sobre seu funcionamento cognitivo, mas fornecer dados sobre a dimensão qualitativa da experiência presente, que é inacessível aos métodos da terceira pessoa, especialmente dotados para o acesso a dados quantitativos e aspectos comportamentais. Do ponto de vista científico, os métodos de terceira e primeira pessoa produzem dados distintos e de valor complementar. Foi essa a abordagem que utilizamos no presente trabalho, onde buscamos investigar a etapa inicial do aprendizado do dispositivo de substituição sensorial por pessoas cegas. Fizemos uma investigação original que combinou o método experimental tradicional, com ordem predefinida de apresentação dos estímulos, ao método clínico-pedagógico, onde os investigadores modificam esse protocolo em função do feedback fornecido pelos voluntários e da entrevista de explicitação, realizada no início e no final do treino.

O estudo parte do entendimento de que a deficiência visual não é um fenômeno natural e meramente fisiológico, mas um fenômeno complexo, de cuja construção participam também fatores sociais, econômicos, culturais, políticos, artísticos, educacionais e tecnológicos. A ideia central é de que as capacidades cognitivas e a amplitude existencial de uma pessoa que não dispõe da visão, mas que recebeu cuidados, educação e oportunidades de participar da vida social e cultural são bastante diferentes e superiores com relação àquela que não dispôs de tais possibilidades. Tal maneira de entender a cegueira encontra referência nas ideias pioneiras de Vigotsky (1997), que indicaram uma abordagem sóciohistórica e um caminho interdisciplinar para os estudos na área. Nessa direção, os trabalhos mais recentes de Sacks (1995), Bach-y-Rita (1997), Sampaio, Maris e Bach-y-Rita (2001), Kastrup (2008) e Weigand (2008) formam um terreno teórico fecundo, onde o tema das novas tecnologias assistivas ganha lugar de destaque por sua possível contribuição para um entendimento dos limites e possibilidades das pessoas com deficiência visual e de sua inclusão social.

\section{Método}

\section{Participantes}

O grupo de voluntários foi constituído de quatro pessoas totalmente cegas, porém com vivências de cegueira diferentes. A idade do grupo variou entre 20 e 66 anos, havendo participantes de ambos os sexos e categoria sócio-profissional variada (tabela 1). Esse leque diversificado de características, embora dentro de uma amostragem reduzida, visou obter dados que servissem de indicadores da vivência do aprendizado inicial do uso do BrainPort ${ }^{\circledR}$ por pessoas diferentes das que constituem geralmente a amostragem clássica neste tipo de pesquisa. São essas pessoas de características 
heterogêneas que, no entanto, serão os utilizadores potenciais desse tipo de tecnologia assistiva na vida cotidiana (Riemer-Reiss \& Wacker, 2000).

Tabela 1: Características dos participantes

\begin{tabular}{|l|l|l|l|}
\hline Participante & Idade & Sexo & Cegueira \\
\hline P1 & 58 & Masculino & Adquirida \\
\hline P2 & 66 & Feminino & Adquirida \\
\hline P3 & 62 & Masculino & Adquirida \\
\hline P4 & 20 & Feminino & Congênita \\
\hline
\end{tabular}

\section{Material}

O BrainPort ${ }^{\mathbb{}}$ é a versão atualmente mais evoluída do TVSS (Tactile-Vision-Substitution-System). Esse sistema foi desenvolvido nos anos 60 pela equipe do Prof. Paul Bach-y-Rita, na Califórnia. Pode-se esque- matizar a composição do TVSS em quatro elementos : (1) uma microcâmera que tem a função de converter a energia luminosa em sinais elétricos; (2) um sistema informático constituído por um computador, podendo ou não se substituir pela câmera; (3) uma caixa de conversão que transforma o sinal visual captado pela câmera em sinal tátil; e (4) uma matriz de estimulação elétrica ou mecânica. No caso do BrainPort ${ }^{\circledR}$, o computador é miniaturizado (palmtop), e a matriz de estimulação é constituída de 100 microeletrodos distribuídos numa superfície de 2,54 por 2,54 cm. A imagem tátil é, assim, explorada com a língua.

Como estímulos, utilizamos peças bidimensionais de diferentes tamanhos e formas, cortadas em isopor branco (tabela 1) e dispostas contra um fundo preto, de modo a maximizarem o contraste. Esse fundo era um quadro de metal de $80 \mathrm{~cm}$ por $50 \mathrm{~cm}$, e as peças eram afixadas através de ímãs. Utilizamos ainda pequenos objetos brancos que os participantes podiam manipular e explorar, como uma caneta.

Tabela 2: Estímulos em ordem preferencial de apresentação

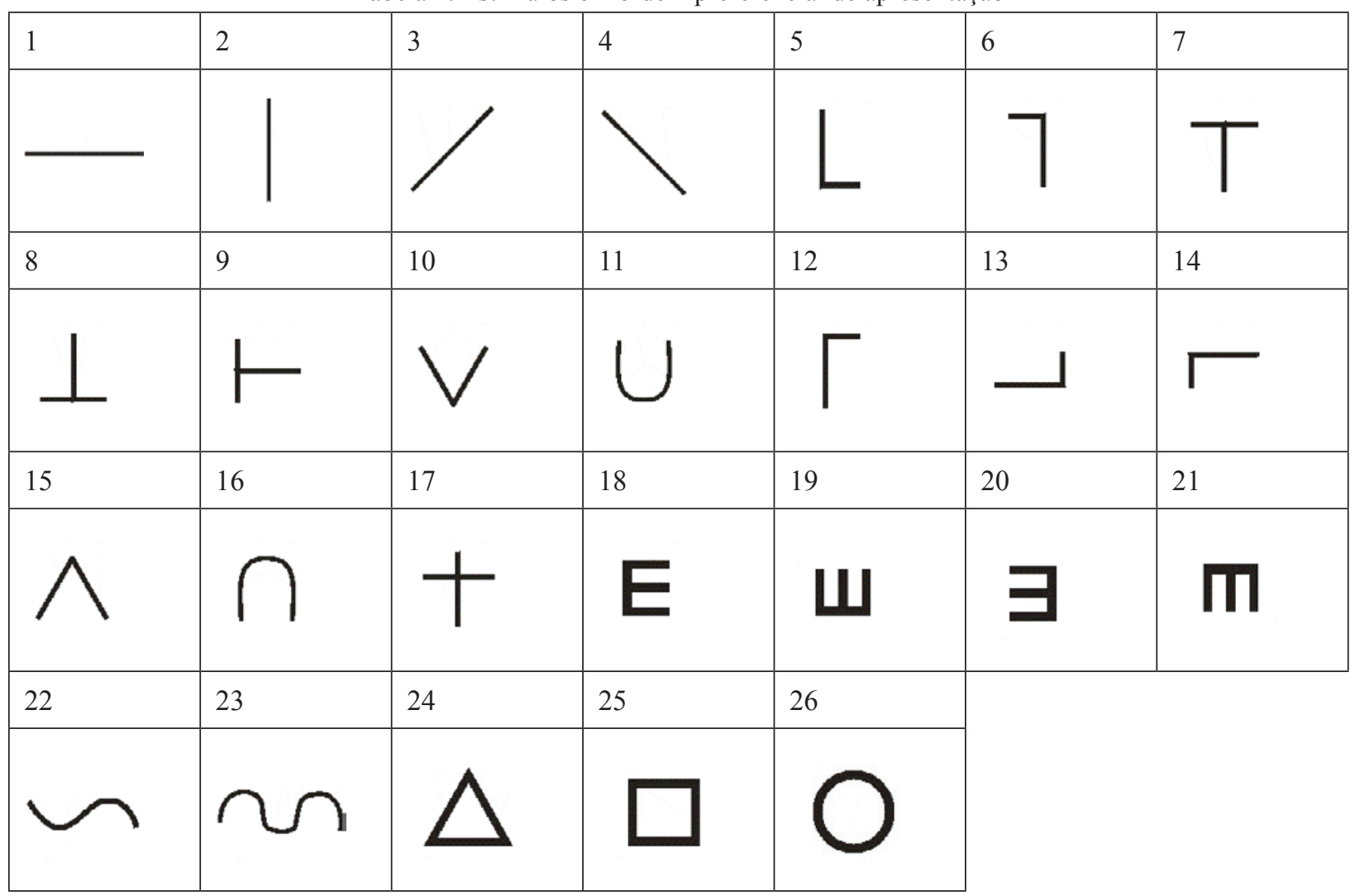

\section{Procedimento}

Foram realizadas sessões de treino diárias de, aproximadamente, 40 minutos, num total de $4 \mathrm{~h} 00$ a 7 h20, dependendo da disponibilidade de cada parti- cipante. Os participantes ficavam sentados a $60 \mathrm{~cm}$ do quadro. A cada sessão eles eram acompanhados por dois experimentadores, um dos quais conduzia o treino e dialogava com o participante, enquanto o outro observava e fazia anotações. 
Antes do início da primeira sessão de treino, todos os participantes receberam uma explicação acerca do funcionamento do dispositivo, bem como dos objetivos da pesquisa. Nesse momento, nos colocamos à disposição para esclarecermos quaisquer dúvidas. Explicamos a cada participante nosso interesse pela aprendizagem do uso do BrainPort ${ }^{\mathbb{B}}$ e tentamos deixar claro que nosso objetivo não era testar uma capacidade específica nem comparar seus desempenhos, mas guiá-los para aprender a usar aquela nova tecnologia.

A apresentação dos estímulos se deu de acordo com uma ordem crescente de dificuldade. A tabela 1 lista os estímulos numa ordem preferencial de apresentação. Entretanto, de acordo com as particularidades do processo de aprendizagem de cada participante, foram introduzidos pequenos desvios e reapresentações do mesmo estímulo. A partir do momento em que o estímulo era afixado ao quadro, o participante era livre para explorá-lo com o BrainPort ${ }^{\mathbb{R}}$, podendo, inclusive, tocá-lo quando achasse necessário, até que fosse capaz de reconhecê-lo. Quando isso acontecia, passava-se para o estímulo seguinte.

Dificuldades foram surgindo ao longo do treino, exigindo a criação de diferentes estratégias para contorná-las. As estratégias variavam, dependendo da natureza da dificuldade. Informações sobre os melhores modos de exploração não se mostraram capazes de dissipálas. Para contorná-las, os experimentadores tiveram que desenvolver práticas e estratégias que acabaram por constituir um método de ensino. Este método, que chamamos de clínico-pedagógico, compreende não apenas instruções para auxiliar os participantes em suas dificuldades de exploração, mas sugere um certo posicionamento por parte dos experimentadores.

Chamamos o método de clínico porque ele atenta para questões que transcendem o nível operacional do aprendizado, levando em consideração a relação do participante consigo mesmo e com o próprio processo que está vivenciando. É preciso deixar claro que não fizemos nem pretendemos fazer um trabalho clínico propriamente dito. Entretanto, reconhecemos a importância de uma dimensão da experiência com o dispositivo que ultrapassa a realização da tarefa. Deixamos os participantes à vontade para expressarem preocupações com o próprio desempenho, expectativas e anseios despertados pelo dispositivo, dúvidas e desconfianças relativas ao propósito e aos métodos da própria pesquisa, etc. Tal abertura para a fala dos participantes foi além da demanda de feedback, em que os participantes são encorajados a darem sua opinião a respeito de como se poderia tornar o próprio dispositivo mais eficiente e confortável. Trata-se, aqui, de uma escuta que busca integrar a fala do participante à própria maneira como será conduzido o treinamento.
Quando os participantes traziam, por exemplo, uma comparação de algum momento do treinamento com eventos passados das suas vidas (acompanhar longitudinalmente um estímulo era como se esforçar para manter o caminhão nos limites da estrada), também nos forneciam instrumentos úteis para a criação de uma maneira específica de propor as tarefas, especialmente quando esbarrávamos em dificuldades.

O método de treinamento era pedagógico porque os pesquisadores estavam menos interessados em testar o desempenho dos participantes do que em criar as condições para o uso do dispositivo. Assim, embora tenham sido feitas anotações sobre o desempenho (para cada estímulo apresentado, anotou-se o sucesso ou fracasso na tarefa de reconhecimento), o objetivo dos treinos era, sobretudo, acompanhar o processo de aprendizado, identificando recorrências e criando soluções para as dificuldades.

A cada nova tarefa, os pesquisadores procuravam ajudar o máximo possível os participantes, dando feedbacks e coordenadas constantes ("agora você está explorando o canto direito"), até que eles dessem sinais de que poderiam fazer sozinhos o que era pedido. Usavam essa estratégia não apenas para ajudá-los a aprender, mas também como uma forma de não deixá-los desistir da atividade. Também lembravam aos participantes que executar determinadas tarefas com o BrainPort ${ }^{\circledR}$ era realmente difícil no início do aprendizado.

Os pesquisadores se posicionavam frente aos erros como sendo comuns e esperados, haja vista o aspecto inabitual da atividade. Lembravam que, no início, era difícil usar o BrainPort ${ }^{\circledR}$, e sempre procuravam, na medida do possível, levar os participantes a pensarem e a entenderem os erros que cometiam. Isso era feito de duas formas. Uma delas era pedindo que eles expusessem as dificuldades que sentiam, tentando identificar os obstáculos e o que poderia ser feito para facilitar determinada atividade. Outra forma era o próprio experimentador levantar hipóteses para explicar as dificuldades do participante, a partir da observação que fazia de sua atividade de exploração. O participante era solicitado a se posicionar a respeito daquilo que era colocado como possível explicação pelo experimentador. Esse também podia dar sugestões ao participante para que ele mudasse sua maneira de explorar o estímulo, procurando observar se elas facilitariam ou não o uso do BrainPort ${ }^{\mathbb{B}}$.

Em relação às entrevistas de explicitação (Vermersch, 2000), elas foram realizadas com o objetivo de explicitar experiências ocorridas durante o aprendizado, acionando as dimensões perceptiva, sensorial e emocional. A condução da entrevista teve como objetivo produzir um processo de tomada de consciência (awareness) de experiências vividas não conscientes, ou seja, implí- 
citas e pré-refletidas. Visou-se à evocação concreta das experiências e à redescoberta de imagens e sensações associadas a ela. As entrevistas foram conduzidas com o objetivo de que o sujeito assumisse a posição de fala encarnada, evitando a posição de fala abstrata, ou seja, pautada em saberes e crenças pré-existentes.

\section{Resultados e discussão}

O volume horário do treino variou entre $4 \mathrm{~h} 00 \mathrm{e}$ $7 \mathrm{~h} 20$ em função dos participantes. Comparando a porcentagem de acertos entre o início e o final do período de treinamento, constatamos que o desempenho inicial parecia ser um bom indicador das capacidades de aprendizagem (cf. tabela 3). No início do treino, três pessoas obtiveram uma boa performance, e uma respondeu de maneira aleatória. As três pessoas mantiveram um bom desempenho até o final do treino: duas delas progrediram, e uma delas manteve a boa performance obtida inicialmente $(100 \%)$. Por outro lado, a pessoa que respondeu de maneira aleatória desde o início do treinamento $(50 \%$ de acertos), manifestou um declínio no final do mesmo (27\%). Apesar de esses dados serem objetivos, cabe ressaltar que eles representam uma simples sugestão de tendência eventual, tendo em vista a limitação numérica e em termos de representatividade da amostra.

Tabela 3: porcentagem de acertos

\begin{tabular}{|c|c|c|}
\hline Participantes & Início do treino & Final do treino \\
\hline P1 & $69 \%$ & $100 \%$ \\
\hline P2 & $50 \%$ & $27 \%$ \\
\hline P3 & $87,5 \%$ & $92 \%$ \\
\hline P4 & $100 \%$ & $100 \%$ \\
\hline
\end{tabular}

\section{As primeiras experiências}

Os participantes descreveram o uso inicial do dispositivo como uma experiência nova e estranha "Ah, é uma sensação, assim, digamos assim... É tentar sentir o tato através da língua. É um negócio com-ple-ta-men-te diferente. Chega a ser até meio estranho" (P3). "Nada assim tão: 'Nossa, que desconfortante!' Mas é lógico que uma coisa nova, numa parte do corpo da gente, vai causar um impacto" (P4). Os participantes também fizeram menção ao medo de levar choque. "Eu pensei em várias coisas, ou que ia dar um choquinho, ou uma formiguinha, como haviam descrito pra mim. Ou que iria, sei lá, sentir um pouco de dor, por menor que seja, até me acostumar com o aparelho. Mas foi normal" (P4). "Na primeira vez eu fiquei meio temeroso em relação ao choque. Eu tenho pavor de choque. Mas não é não, é apenas um formigamento" (P3). Para alguns participantes houve incômodo com a salivação. "No primeiro dia, foi uma salivação danada ao pôr aquilo na boca. Mas, depois que a gente pega o jeito, nem saliva mais. É um pouco incômodo você ficar com aquilo na boca, mas é superável" (P2). Em função da dificuldade inicial, os participantes observaram que a utilização do dispositivo requer muita atenção. "Eu tive que ter um pouco de concentração, porque é difícil. Como eu falei, é uma coisa nova. Então, você tem que se concentrar" (P4). Os participantes descreveram a experiência como um tato na língua. "Com o aparelho, é como se fosse você tocando naquilo" (P4). A experiência foi descrita como distinta do tato com as mãos, por não haver experiência com o material de que é feito o estímulo, mas apenas com a forma. "Não é só você achar o objeto e fechar a mão. Você tem que procurar o objeto, tem que perceber como é que é a forma desse objeto" (P4). Tudo isto deve ser feito através de grande concentração na língua, mesmo que a mão fique "coçando". "Dá vontade de tocar no objeto, mas... O deficiente, ele está acostumado a lidar com as mãos. Para tudo o deficiente usa as mãos. As mãos são seus olhos. Quando a gente lida com uma coisa que a gente não pode usar as mãos, que tá na minha frente, mas eu não posso tocar, eu tenho que ver com a língua. Mas dá muita vontade de tocar. Mas só no começo" (P4). "Na medida em que a câmera vai contornando a figura, ele contorna aquela figura também na língua. Como se ele tivesse desenhando a mesma figura na língua, fazendo uma planta, só com as beiradas da figura. A sensação é de um desenho na língua, através de vários impulsos, de vários microimpulsos, muito rápidos" $\left(\mathrm{P}^{1}\right)$. Perguntado se o estímulo tinha aspecto descontínuo e fragmentado, respondeu que não. "É como se fosse uma corrente contínua, com uns pulinhos, mas rápido, muito rápido. A cada milésimo de segundo, um pulinho. Não dava nem tempo de chegar a um segundo. Eu tenho consciência porque eu experimentei. Eu estava com o aparelho na boca e dava pra perceber. À medida que a gente vai mexendo com a câmera, a intensidade dos pulinhos também vai se mexendo pros lados, pra cima, pra baixo, pra direita, pra esquerda, igual está na figura (P5). Nem todos os participantes tiveram medo, e alguns não demonstraram qualquer ansiedade. Um deles afirmou que ficou tranquilo, em função de conhecimentos que possuía. "Foi normal, natural. Pra quem estudou eletrônica e tem noções de eletricidade e outras coisas relacionadas a esses estímulos, isso é normal" (P5).

Observamos o aparecimento de estratégias que os próprios participantes criavam a fim de diminuirem a estranheza da experiência. Um participante, por exemplo, recorria à sua experiência anterior como caminhoneiro para conseguir se concentrar melhor na exploração de uma linha reta. Ele comparou a capacidade de se manter seguindo a linha, sem perdê-la do campo de visão da câmera, à sua experiência de ter que manter o caminhão 
dentro dos limites da estrada. Esse tipo de estratégia evidenciou a importância de incorporar elementos presentes na experiência anterior dos participantes às atividades de aprendizado.

\section{Dificuldades}

Durante os treinos, algumas dificuldades foram se evidenciando, sendo algumas de caráter mais resistente, e outras passageiras. As dificuldades eram relativas ao acoplamento sensório-motor, ao movimento da cabeça e do corpo e ao não cumprimento de certas expectativas em relação à qualidade da experiência. Embora outras dificuldades, referentes à relação com os pesquisadores, com o dispositivo e com a própria cegueira tenham surgido e se mostrado importantes, neste artigo analisaremos apenas as três primeiras. Buscaremos descrevêlas, discutindo suas possíveis causas e mostrando as estratégias utilizadas na tentativa de superá-las.

\section{Dificuldades para o acoplamento sensório- motor}

Estudos anteriores demonstraram o papel essencial desempenhado pela ação para a percepção com dispositivos de substituição sensorial (Bach-y-Rita, 1972). Demonstrou-se que, se o sujeito não tiver liberdade para deslocar a câmera ativamente (é esse o caso quando a câmera é mantida em repouso ou quando o experimentador a desloca), suas capacidades de reconhecimento e discriminação permanecem muito limitadas, e a estimulação é sentida na língua. Entretanto, se o sujeito for livre para mover a câmera, desenvolve boa capacidade de reconhecimento de formas e objetos; além disso, com algumas horas de treino (de 5 a 10 horas), o sujeito passa a perceber os objetos diretamente no espaço tridimensional à sua frente (distalização), deixando de ter a sensação na língua. Observa-se, assim, que o puro aporte sensorial não dá lugar a uma percepção propriamente dita. É apenas quando as diferentes sensações são percebidas como consequências de determinados movimentos realizados pelo sujeito que se desenvolve o reconhecimento de formas e que, mais tarde, emerge a percepção do objeto distal.

Em nosso estudo, em função do número de horas de treino, nenhum dos participantes chegou à distalização. Mas, mesmo o simples reconhecimento de formas (percebidas ou não num espaço tridimensional externo) exige que o sujeito interprete as sensações como consequências das suas ações. Ou seja, um certo grau de acoplamento sensório-motor é necessário para o uso do dispositivo, mesmo nos momentos anteriores à distalização. O conceito de acoplamento estrutural (Maturana \& Varela, 1995) nomeia uma relação sensório-motora imediata com o objeto técnico que se distingue da relação mediada por informações ou representações.
Podem-se entender as relações mediada e imediata como pólos de um contínuo. Nessa direção, é possível observar-se que os participantes apresentaram diferentes graus de acoplamento sensório-motor, variando de um acoplamento precário e quase nulo até um acoplamento muito próximo ao exigido para a distalização. Um dos participantes (P1) descobriu algumas consequências sensoriais de seus movimentos em momentos específicos e bem demarcados. Na sessão 5, por exemplo, contou ter notado subitamente que, quando movia a cabeça para um lado, a estimulação se movia no sentido oposto. Já na sessão 2, desenvolveu uma estratégia de microvarredura. Após cada um desses insights, observamos um salto no seu desempenho, acompanhado, inclusive, de uma maior motivação. Outros dois participantes (P3 e P4), mesmo não tendo verbalizado esse tipo de insight, apresentaram sinais claros de desenvolvimento nesse sentido. Afinal de contas, o sucesso numa tarefa de reconhecimento de forma já é um indicador de acoplamento sensório-motor.

Uma das participantes (P2), no entanto, apresentou dificuldades em relação a esse tópico. Sua curva de aprendizagem se deu de maneira muito imprevista: na primeira sessão, apresentou um alto grau de consciência das consequências sensoriais da ação; da segunda sessão em diante, porém, a expectativa inicial foi sendo cada vez mais frustrada. A participante apresentou extrema dificuldade em distinguir entre as diferentes orientações espaciais do L. Por mais que treinássemos a tarefa e sugeríssemos estratégias de exploração e discriminação, não chegou a distinguir, por exemplo, entre o L e sua imagem girada em 180 graus. Seu avanço no reconhecimento de formas também ficou prejudicado. Ao final de 6 horas de treino, ainda não era capaz de reconhecer outras formas além da linha horizontal, da linha vertical e da diagonal esquerda (mesmo entre essas formas, houve retrocessos, como foi o caso da vertical). Numa tarefa em que o estímulo realizava um movimento simples (translação para a direita, para a esquerda, para cima ou para baixo), a participante, em contraste com os outros, não foi capaz de indicar a direção correta, mesmo com a ajuda dos experimentadores.

Na tentativa de entender o motivo do mau desempenho dessa participante, formulamos duas hipóteses explicativas inter-relacionadas. A primeira é de que ela teve dificuldade em acoplar os polos sensorial e motor de sua experiência. A segunda é de que ela não entendeu suficientemente o funcionamento do dispositivo, apesar das explicações fornecidas no início e durante o treinamento. Os dados sugerem a adequação de tais hipóteses. Numa demonstração de que não compreendera a importância do acoplamento sensório-motor, afirmou certa vez que estava se esforçando por se concentrar puramente na estimulação recebida na língua, 
ignorando seus próprios movimentos. Ela acreditava que a sensação era suficiente para o reconhecimento das formas. Ora, sabemos que essa maneira de usar o BrainPort $^{\circledR}$ não produz bons resultados. Como mostra Lenay (2006), é preciso, por um lado, que o sujeito interprete a estimulação como função de seus movimentos; por outro lado, ele deve desenvolver estratégias de exploração em função da estimulação recebida. A estratégia da referida participante, que consistiu em considerar apenas a sensação, desprezando o movimento, falha em satisfazer a esses dois pré-requisitos. Em outro momento, a mesma participante revelou incompreensão acerca do funcionamento do BrainPort ${ }^{\circledR}$ ao afirmar estar sendo atrapalhada por uma claridade que era, na realidade, uma particularidade de sua cegueira total e que comparecia o tempo todo na parte superior esquerda do que seria o seu campo visual. Isso nos levou a concluir que ela não havia compreendido que o BrainPort ${ }^{\circledR}$ captava a energia luminosa, transformando-a em estimulação eletrotátil. Ao que tudo indica, ela estava fazendo confusão entre a claridade que ela percebia como própria de sua cegueira e a luz captada pela câmera.

Epstein, Hugues, Schneider e Bach-y-Rita (1986) apontaram que, se os sujeitos não recebem qualquer informação sobre o dispositivo, não chegam à distalização, mesmo que consigam apreender a existência de uma relação entre seus movimentos e o aporte sensorial. É apenas quando entendem o funcionamento básico do dispositivo que eles se tornam capazes de usá-lo adequadamente. No caso do nosso estudo, os participantes receberam informação sobre o BrainPort ${ }^{\circledR}$. Ainda assim, um dos participantes teve muita dificuldade em desenvolver capacidades de discriminação e reconhecimento.

Constatamos que a mera transmissão de informação sobre o funcionamento do BrainPort $^{\circledR}$ não é suficiente para o seu uso. O usuário deve ser capaz não apenas de compreender as informações recebidas, mas também de vivenciá-las corporalmente, a partir de suas ações concretas. Apenas assim é possível entender a surpresa do participante P1 ao "descobrir" subitamente, como se tratasse de algo completamente novo, algo que já lhe havíamos explicado desde o começo. É que, naquele momento, ele o descobriu corporalmente e por si mesmo. Ao que tudo indica, nenhuma informação, por mais detalhada que seja, pode substituir a aprendizagem direta. Daí, ensinar algo vem a ser, mais precisamente, criar condições para que tal aprendizagem tenha lugar.

Todos esses resultados nos levaram a supor a existência de uma plataforma básica necessária para o uso do BrainPort ${ }^{\mathbb{B}}$. Tal plataforma consiste (a) numa compreensão do funcionamento básico do dispositivo e (b) num certo grau de acoplamento sensório-motor, constituído através de suas ações concretas. Se o usuário não estiver de posse desses dois conhecimentos, seu avanço estará apenas prejudicado e, talvez, mesmo impedido. O problema para o experimentador é precisamente que tal plataforma deve ser adquirida pelo usuário num movimento que ninguém pode realizar em seu lugar. O presente estudo aponta para estratégias de ensino dessa plataforma básica para populações heterogêneas, com base no método clínico-pedagógico.

\section{Dificuldades relativas ao movimento de cabeça e pescoço}

Desde o início do treino, surgiram algumas dificuldades em relação aos movimentos da cabeça e do pescoço, assim como à capacidade de mantê-los estabilizados. Já que a câmera é fixada à testa, faz-se necessário um controle bastante concentrado desses movimentos. Afinal, é sobretudo através de movimentos da cabeça que o campo vai ser explorado. O uso do dispositivo envolve tanto uma exploração mais ampla do campo total na busca do estímulo, chamada varredura, quanto uma exploração dos próprios estímulos por movimentos de menor amplitude, restritos à área ocupada pelo estímulo. Sua função não é encontrar o estímulo no campo, mas explorar seu contorno e seus limites. No início, é importante que os participantes consigam mover amplamente cabeça e pescoço e, em seguida, os movimentos devem ser mais precisos, exigindo maior estabilidade a fim de evitar que o estímulo saia do campo de exploração.

Para os dois tipos de exploração descritos acima, o que importa, em última análise, é o deslocamento da câmera. De maneira geral, isso pode ser alcançado através de dois tipos de movimento: (a) um movimento de translação do tronco, em que a cabeça é deslocada junto com o corpo e (b) um movimento de rotação do pescoço. Como se pode perceber, (b) é um movimento mais econômico e adequado à tarefa em questão.

Durante as sessões, observamos que todos os participantes sentiam dificuldade na execução dos movimentos de rotação do pescoço, prejudicando os dois tipos de exploração caracterizados acima. A atividade de varredura do quadro sobre o qual se encontrava o estímulo era bastante prejudicada pela dificuldade em fazer movimentos amplos de rotação. Predominava uma movimentação em bloco de todo o tronco, uma tendência a mover o corpo todo para deslocar a câmera que estava presa à testa. Uma vez encontrado o estímulo, a estratégia de exploração exige movimentos de amplitude reduzida, bem como certa estabilidade para um controle mais fino. Algumas vezes, os participantes perdiam o estímulo devido a uma falta de controle mais apurado desses movimentos. Essas dificuldades foram 
mais marcantes no início do treino, mas permaneceram até o final. Esse mesmo tipo de dificuldade também foi relatado por Guarniero (1977), que achava difícil realizar o movimento de abaixar a cabeça, vendo-se obrigado a dobrar os joelhos e o tronco para explorar o chão.

Algumas vezes fazia-se necessária uma intervenção mais ativa do experimentador, guiando com as mãos a cabeça do participante, buscando mostrar-lhe que era possível forçar um pouco mais o movimento da sua cabeça, realizando assim um movimento mais econômico e mais adequado à situação do que o movimento em bloco do tronco. Uma dessas intervenções, após ser repetida algumas vezes, obteve resultado excelente, promovendo um grande salto no desempenho do participante em questão (P4). Ficou claro que o acoplamento com o dispositivo pode modificar o próprio corpo do percebedor, criando para ele um novo campo de ações possíveis (Lenay, Canu, \& Villon, 1997). Habitualmente, o movimento da cabeça e do pescoço em uma pessoa cega é menos útil que entre os videntes, já que tais movimentos são requeridos para a exploração visual do ambiente (Hatwell, 2003). Porém, se entendemos a tecnologia como um agente transformador do próprio homem, e não apenas do mundo em que ele vive, podemos então compreender as tecnologias de substituição sensorial como modificadoras da experiência e do próprio corpo do usuário. Isso porque, quando se faz uso dessas tecnologias, novas ações impõem-se ao corpo como condições para a percepção (Gapenne, Lenay, \& Boullier, 2001). Uma delas é exatamente o movimento de rotação da cabeça e do pescoço, menos utilizado pelos cegos em seu dia-a-dia. Isso pode explicar tais dificuldades, sugerindo que outras formas de intervenção, como fisioterapia e práticas de expressão corporal, podem ser utilizadas de forma complementar aos treinos com tais dispositivos, visando a uma maior flexibilidade de determinadas partes do corpo, que são indispensáveis para um melhor uso de tais tecnologias.

\section{Dificuldades relativas à defasagem entre a expectativa e a qualidade da experiência}

Nas entrevistas de explicitação, os participantes evidenciaram uma grande mobilização com a experiência. Alguns deles relataram terem tido grande expectativa em relação ao dispositivo, especialmente no que concerne à possibilidade de ver. Tal tecnologia parece despertar uma série de fantasias envolvendo a visão. Em nosso estudo, alguns participantes- cegos tardios- sentiram certa decepção ao utilizarem o aparelho pela primeira vez, pois acreditavam que a experiência com o BrainPort ${ }^{\circledR}$ seria qualitativamente mais parecida com a visão.

Perguntado como havia sido a experiência no início, um participante afirmou: "Eu pensei que, sei lá... eu... é... Eu achava que tinha mais coisas" (P1). Continuou dizendo que pensava que a experiência seria mais rica, talvez não exatamente igual à visão, mas... algo que ele não sabia explicar direito. Em seguida, revelou que a utilização daquela tecnologia havia despertado nele a questão da existência de um chip para que cegos pudessem ver: "Aliás, eu até já sonhei com isso. Eu tinha um sonho há uns tempos atrás com um olho biônico, essas coisas todas que a gente ouve falar muito". Segundo sua descrição: "Eu ficava assim imaginando, assim, coisas que a gente vê, as figuras... A gente lembra muito de Flash Gordon, ficção científica, robôs com antenas. Já estava me imaginando assim antenado". E concluiu: "Porque o que a gente quer mesmo é essa autonomia". Outro participante, numa expressão manifesta de seu desejo de ver, exclamou durante o primeiro treino: "Ué, eu não tô vendo!" (P3). Perguntado se costumava se lembrar da experiência produzida pelo dispositivo após o término da sessão de treino, ele traz à cena a seguinte interrogação. "Eu gostaria de saber se após a aprovação desse aparelho - sei que ainda tá em teste, ainda não se tem certeza - se aquele aparelhinho lá, aquela câmera que tá na testa, se ela vai ser, se ela vai continuar com a pessoa que tiver necessitando de enxergar". Frente à resposta de que o objetivo a longo prazo seria a utilização do equipamento pelos cegos em sua vida cotidiana, perguntou se seria possível, ao final, "eternizar" a câmera na testa. Outro momento em que se fez evidente a expectativa em relação à qualidade da experiência foi a alusão, acima descrita (seção 7.2), que uma participante (P2) fez à claridade que enxergava como interferindo na tarefa de reconhecimento. Parece que só é possível fazer confusão entre essa claridade e a estimulação recebida através do BrainPort ${ }^{\circledR}$ caso se acredite que essa última porte também algum tipo de claridade, ou seja, uma qualidade visual. Como a participante havia presenciado uma descrição do fenômeno da distalização, é possível que ela tenha imaginado algo acerca da qualidade de tal percepção, criando a expectativa de que, de um momento para o outro, a distalização ocorresse, e a experiência se tornasse visual.

Bach-y-Rita (1997) observara que o dispositivo de substituição sensorial não é capaz de produzir uma experiência de caráter emocional. Todavia, pesquisas mais recentes indicam que a natureza da tarefa pode facilitar a emergência da experiência emocional (Segond et al., 2005; Segond, Weiss, \& Sampaio, 2007). Lenay et. al (1997) apontaram que algumas características da experiência provocada por tal dispositivo, como a ausência de cores e a limitação dos movimentos da câmera, são fatores que contribuem para o seu abandono. Cabe ressaltar, no entanto, que essas limitações estão paulatinamente sendo superadas com a evolução tecnológica (Aiello, 1998). De todo modo, as recorrentes 
controvérsias apontam a necessidade de continuidade dos estudos. A percepção propiciada pelo BrainPort ${ }^{\mathbb{B}}$ possui alguns elementos em comum com a percepção visual (paralaxe, perspectiva, ilusões visuais, distalidade) e com a percepção tátil (exploração continuada das formas, em contraste com a instantaneidade da visão, predominância da sensação na língua no início do treino), mas não se identifica com nenhuma das duas em todas as suas características. Portanto, é importante deixar claro para os participantes que essa experiência consiste numa nova forma de percepção, com características próprias. Caso contrário, pode surgir uma forte decepção, configurando um entrave para a aprendizagem, já que a frustração do desejo de ver pode reduzir a motivação e diminuir o interesse do participante pelo treino e pelo próprio uso do dispositivo.

É preciso lembrar que novas tecnologias colocam problemas. No entanto, a noção de problema pode assumir dois sentidos: o obstáculo e a invenção (Kastrup, 2000). No caso em questão, as atividades propostas possuíam um caráter de estranheza que poderia funcionar como um obstáculo ou como desafio para a aprendizagem. É certo que novas tecnologias geram efeitos de produção de subjetividades e de transformação social (Guattari \& Rolnik, 1986; Lévy, 1994). O potencial transformador da utilização de tecnologias como computadores e câmeras fotográficas por grupos minoritários tem sido objeto de diversos estudos em psicologia social, realizados tanto no setor escolar quanto de saúde mental (Demoly \& Maraschin, 2007; Francisco, Axt, $\&$ Maraschin, 2007). O fotógrafo cego Bavcar (2003) faz relatos impressionantes de sua experiência com a fotografia. Nesses domínios, a possibilidade de produzir imagens e auto-retratos teve efeitos transformadores e acionou processos de invenção de si. Em nosso estudo, ficou evidente que o caráter de novidade da experiência poderia obstaculizar ou potencializar as transformações subjetivas e sociais que as tecnologias assistivas possibilitam. A etapa inicial do processo de aprendizagem surgiu como um campo de experimentação, suscitando sensações e sentimentos ambíguos como o medo, o gosto pela aventura e mesmo o sonho de voltar a ver.

Durante os treinos, procuramos acolher os relatos dos participantes em relação a esta estranheza e à quebra de suas expectativas. Com isso, buscamos reiteradamente esclarecer, especialmente para os portadores de deficiência visual adquirida, que aquela experiência jamais seria idêntica à que eles tiveram com a visão. Procuramos enfatizar a importância de se estudar e desenvolver tal tecnologia, já que ela pode dar acesso aos cegos a novas experiências capazes de ajudá-los a viver e a se deslocar melhor no espaço, contribuindo para sua inclusão social, sem a pretensão de ser exatamente como a visão.

\section{Conclusões}

No presente estudo, acompanhamos a etapa inicial do processo de aprendizagem para utilização de um dispositivo de substituição sensorial por quatro pessoas cegas. A escolha de uma amostra heterogênea permitiu que nos confrontássemos com as dificuldades que surgem no uso do dispositivo na vida cotidiana, tornando possível criar estratégias para superá-las. Os dados quantitativos, de terceira pessoa, mostraram que o desempenho inicial parece ser um bom indicador das capacidades de aprendizagem. Os dados em primeira pessoa complementaram os de terceira, ao detalhar a dimensão de experiência do processo de aprendizagem.

Dentre as dificuldades surgidas durante o treinamento, o método clínico-pedagógico permitiu superar algumas, enquanto outras se mostraram mais resistentes. As principais dificuldades foram relativas ao acoplamento sensório-motor, ao movimento da cabeça e ao não cumprimento de certas expectativas em relação à qualidade da experiência. Dadas as limitações do estudo, não foi possível dividir as dificuldades entre superáveis e insuperáveis. Por certo o método clínico-pedagógico permitiu superar dificuldades de alguns participantes. Outras foram mais resistentes, como o medo de choque de uma participante (P2), que persistiu até o final do treinamento, levando-a a relutar em aumentar a intensidade da estimulação até um nível suficiente para o bom uso do dispositivo.

Assim, nosso estudo sugere que, para a aprendizagem bem sucedida do uso do BrainPort ${ }^{\circledR}$, a prática é condição necessária, embora muitas vezes insuficiente. Faz-se necessária uma prática acompanhada de perto por uma segunda pessoa, que assuma uma postura clínico-pedagógica e leve em consideração a experiência vivida pelo usuário. Realizada desta maneira, tal prática pode criar melhores condições para o desenvolvimento de estratégias de superação de dificuldades próprias ao aprendizado de uma nova tecnologia de percepção para pessoas com deficiência visual, o que pode vir a contribuir, no futuro, para a ampliação do território existencial de uma pessoa com deficiência visual e para sua participação mais efetiva na vida social.

\section{Notas}

* Este trabalho foi realizado durante a estadia da Profa.Eliana Sampaio no Instituto de Psicologia da UFRJ, de outubro 2007 a abril 2008. Agradecemos calorosamente a colaboração dos participantes, bem como a do Instituto Benjamin Constant.

1 Uma quinta pessoa participou apenas de uma sessão de treino e fez uma entrevista. 


\section{Referências Bibliográficas}

Aiello, G. L. (1998). Multidimensional electrocutaneous stimulation. IEEE Transactions on Rehabilitation Engineering, 6(1), 95-101.

Bach-y-Rita, P. (1972). Brain mechanisms in sensory substitution. New York: Academic Press.

Bach-y-Rita, P. (1997). Substitution sensorielle et et qualia. In J. Proust (Ed.), Perception et intermodalité: Approches actuelles de la question de Molyneux (pp. 81-100). Paris: PUF.

Bavcar, E. (2003). Um outro olhar. Humanidades, 49, 121-125.

Chebat, D. R., Rainville, C., Kurpers, R., \& Ptito, M. (2007). Tactile-'visual' acuity of the tongue in early blind individuals. Neuroreport, 18(18), 1901-1904.

Demoly, C. \& Maraschin, C. (2007) Escrituras de professores na convergência de mídias. Reflexão e Ação, 15, 1-7.

Epstein, W., Hugues, B., Schneider, S., \& Bach-y-Rita, P. (1986). Is there anything out there? A study of distal attribution in response to vibrotactile stimulation. Perception, 15, 275-284.

Francisco, D., Axt, M., \& Maraschin, C. (2007). Informática e saúde mental: caminhos de uma oficina. RENOTE. Revista Novas Tecnologias na Educação, 5, 1-16.

Gapenne, O. , Lenay, C., \& Boullier, D. (2001). Assistance, suppléance et substitution: Trois modalités distinctes du couplage humain/technique. In Proceedings of the Conference JIM'2001 (142-145). Metz, France.

Guarniero, G. (1974). Experience of tactile vision. Perception, $3,101-104$.

Guarniero, G. (1977). Tactile vision: A personal view. Journal of Visual Impairment \& Blindness, 71, 125-130.

Guattari, F. \& Rolnik, S. (1986). Micropolítica-catografias do desejo. Petrópolis, RJ: Vozes.

Hatwell, I. (2003). Psychologie cognitive de la cécité précoce. Paris: Dunod.

Kastrup, V. (2000). Novas tecnologias cognitivas: o obstáculo e a invenção. In N. Pellanda \& E. Pellanda (Orgs.), Ciberespaço: um hipertexto com Pierre Lévy (pp. 38-54). Porto Alegre: Artes \& Ofícios.

Kastrup, V. (2007). A invenção na ponta dos dedos: a reversão da atenção em pessoas com deficiência visual. Psicologia em Revista, 13(1), 69-89.

Kastrup, V. (2008). O lado de dentro da experiência: atenção a si e produção de subjetividade numa oficina de cerâmica para pessoas com deficiência visual adquirida. Revista Psicologia: Ciência e Profissão, 28(1), 186-199.

Lenay, C. (2006). Enaction, externalisme et suppléance perceptive. Intellectica, 43, 27-52.

Lenay, C., Canu, S., \& Villon, P. (1997). Technology and perception: The contribution of sensory substitution systems. In 2nd International Conference on Cognitive Technology (44-53). Aizu, Japan.

Lévy, P. (1994) As tecnologias da inteligência. Rio de Janeiro: Ed. 34.

Maturana, H. \& Varela, F. (1995). A árvore do conhecimento. Campinas: Editorial Psy.

Phillips, B. \& Zhao, H. (1993). Predictors of assistive technology abandonment. Assistive Technology, 5(1), 36-45.

Riemer-Reiss, M. \& Wacker, R. R. (2000). Factors associated with assistive technology discontinuance among individuals with disabilities. Journal of Rehabilitation, 66(3), 44-50.
Sacks, O. (1995). Um antropólogo em Marte: sete histórias paradoxais. São Paulo: Cia das Letras.

Sampaio, E., Maris, S., \& Bach-y-Rita, P. (2001). Brain plasticity: 'Visual' acuity of blind persons via the tongue. Brain Research, 908, 204-207.

Segond, H., Weiss, D., \& Sampaio, E. (2005). Human spatial navigation via a visuo-tactile sensory substitution system. Perception, 34, 1231-1249.

Segond, H., Weiss, D., \& Sampaio, E. (2007). Can we propose a tactile vision substitution system to blind babies? Journal of Visual Impairment and Blindness, 101, 32-43.

Varela, F. \& Shear, J. (2001). Introdução. In F. Varela \& J. Shear (Eds.), The view from within: First-person methodologies (pp. 1-14). Exeter: Imprint Academic.

Vermersh, P. (2000). L'entretien d'explicitation. Issy-lesMolineaux: ESF.

Vygotski, L. (1997). Fundamentos de defectología. Obras Escogidas V. Madrid: Visor. (Texto original publicado em 1929).

Weygand, Z. (2008). Vivre sans voir. Lês aveugles dans la société française du Moyen Age a Louis Braille. Paris: Creaphis.

Virgínia Kastrup é psicóloga e doutora em Psicologia pela PUC-SP (1997) e pós-doutorada no CNRS, Paris (2002). É Professor Associado da Universidade Federal do Rio de Janeiro, atuando no Programa de Pós-graduação em Psicologia e pesquisadora do CNPq. Endereço: Rua Cristóvão Barcelos, 280/603 Laranjeiras CEP 22245-110. Rio de Janeiro, RJ, Brasil. Email: virginia.kastrup@gmail.com

Eliana Sampaio é psicóloga, doutora em Psicologia pela Ecole de Hautes Etudes en Sciences Sociales/CNRS, Paris (1986), pos-doutourada na "University of MadisonWisconsin”, USA (1992), Livre Docente "Habilitation à diriger des recherches" pela Université Paris V (1994). Atualmente é "Professeure titulaire de la chaire Handicap", e diretora do "Laboratoire Brigitte Frybourg" do

"Conservatoire National des Arts et Métiers", Paris-França. Endereço : 2 rue Conté - case 211 - 75003

Paris, França.

Email: eliana.sampaio@cnam.fr

Maria Clara de Almeida e Filipe Herkenhoff Carijó são graduados em Psicologia pela UFRJ e foram bolsistas de iniciação científica do CNPq e FAPERJ, respectivamente.

O aprendizado da utilização da substituição sensorial visuo-tátil por pessoas com deficiência visual: primeiras experiências e estratégias metodológicas

Virgínia Kastrup, Eliana Sampaio, Maria Clara de Almeida e Filipe Herkenhoff Carijó

Recebido: $12 / 12 / 2008$

Revisão: 20/04/2009

Aceite: 03/05/2009 